\title{
Economic Evaluation of Timely Versus Delayed Use of Tumor Necrosis Factor Inhibitors for Treatment of Psoriatic Arthritis in the US
}

Vibeke Strand · Elaine Husni · Jenny Griffith $\cdot$ Zheng-Yi Zhou · James Signorovitch $\cdot$

Arijit Ganguli

Received: August 3, 2016/ Published online: September 15, 2016

(c) The Author(s) 2016. This article is published with open access at Springerlink.com

\section{ABSTRACT}

Introduction: The present study aimed to evaluate clinical outcomes and costs associated with timely versus delayed use of tumor necrosis factor inhibitors (TNFis) among patients with moderately to severely active psoriatic arthritis (PsA) with and without moderate/severe psoriasis (Ps) from a US payer's perspective.

Methods: An economic model evaluated PsA patients initially treated with a TNFi (timely TNFi use) or apremilast (delayed TNFi use). Patients without joint (American College of Rheumatology 20\%, [ACR20]) improvement

Enhanced content To view enhanced content for this article go to http://www.medengine.com/Redeem/ DDB5F06042F6F498.

V. Strand

Stanford University, Palo Alto, CA, USA

E. Husni

Cleveland Clinic, Cleveland, $\mathrm{OH}$, USA

J. Griffith · A. Ganguli

AbbVie Inc., North Chicago, IL, USA

Z.-Y. Zhou $(\varangle) \cdot$ J. Signorovitch

Analysis Group Inc., Boston, MA, USA

e-mail: Jenny.Zhou@analysisgroup.com either switched TNFis or initiated one. ACR20 responses were evaluated for all patients and skin responses by Psoriasis Area Severity Index 75\% (PASI75) for those with concomitant PsA and Ps. Published randomized controlled trials and publicly available databases provided model inputs. Effectiveness measures included 1-year responses and number needed to treat (NNT). Direct costs, costs per responder, and incremental costs per responder were calculated.

Results: After 1 year, timely TNFi-treated patients had higher ACR20 responses (70.4\% vs. $59.6 \%)$ and lower NNTs (1.42 vs. 1.68) compared with delayed use. Among PsA + Ps patients, timely TNFi use was associated with higher ACR20 + PASI75 responses (41.0\% vs. $30.0 \%$ ) and lower NNTs (2.44 vs. 3.33). Cost per ACR20 responder was higher (\$56,492 vs. $\$ 52,835$ ) among PsA patients without Ps; with concomitant Ps, cost per ACR20 + PASI75 responder was lower for timely TNFi use $(\$ 100,954$ vs. $\$ 111,686)$. Incremental costs per responder for timely versus delayed TNFi were $\$ 76,823$ in PsA and \$71,791 in PsA and Ps.

Conclusion: Timely use of TNFis is a cost-effective strategy for the management of 
PsA based on improvements in both joint and/ or skin disease.

Funding: AbbVie Inc.

Keywords: Anti-tumor necrosis factor agents; Apremilast; Economic analysis; Psoriatic arthritis

\section{INTRODUCTION}

Psoriasis (Ps) affects an estimated 7.4 million adults (3.2\% of the total population) in the US [1]. Nearly one in three psoriasis patients will develop psoriatic arthritis (PsA) [2, 3], a chronic inflammatory arthropathy typically associated with Ps of the skin or nails and includes other manifestations such as enthesitis, dactylitis, uveitis, and spondylitis [4]. Given the progressive nature of the disease, nearly half of PsA patients will develop irreversible bone erosions/joint destruction [5], leading to impaired physical function [6], higher likelihood of presenteeism and work disability [7-9], and, consequently, high direct and indirect costs [10-12]. Several treatment options are available to manage symptoms and inhibit structural disease progression. The recently published Group for Research and Assessment of Psoriasis and Psoriatic Arthritis (GRAPPA) treatment recommendations (2016) strongly recommend disease-modifying anti-rheumatic drugs (DMARDs), including methotrexate (MTX), leflunomide, sulfasalazine and tumor necrosis factor inhibitors (TNFis) as initial treatment for patients with PsA [13]. For patients who fail to respond to DMARDs, biologics (TNFis, interleukin [IL] 12/23 or IL 17 inhibitors) or a phosphodiesterase- 4 inhibitor (PDE4i) are suggested [13].

Recently, apremilast, a PDE4i, was approved for treatment of active PsA [14] based on demonstrated improvement in the signs and symptoms of active PsA relative to placebo in several randomized controlled trials (RCTs) that did not evaluate structural joint damage [15-19]. While there are no head-to-head RCTs comparing the efficacy of apremilast versus a TNFi, treatment responses were substantially lower in individual recent Phase III RCTs with apremilast $[16,20]$ than with TNFis in patients with moderately to severely active PsA [21, 22], despite generally similar inclusion criteria. By week 16 in phase III RCTs (PALACE 1-3; NCT01172938, NCT01212757, NCT01212770), $30-41 \%$ of apremilast-treated DMARD incomplete responders (DMARD-IR) achieved American College of Rheumatology 20\% responses (ACR20) [16-19], and 21-22\% patients achieved Psoriasis Area Severity Index 75 (PASI75) responses (PALACE-3; NCT01212770) [18]. In contrast, 58-68\% of DMARD-IR patients treated with TNFis achieved ACR20 and 51-59\% PASI75 responses in 12-16 weeks [21, 22]. Additionally, an indirect comparison of RCT data found that apremilast has similar efficacy to MTX in treating a MTX-naïve population [23].

Both TNFis and the PDE4i have been recommended by GRAPPA as treatment options after initial DMARD failure. However, it is not clear whether using apremilast or a TNFi first may have different clinical and/or economic impacts on patient outcomes. Use of apremilast after DMARD failure may result in a delay in prescribing TNFis known to reduce structural progression. The current study was designed to robustly model the economic impact of timely versus delayed use of TNFis in patients with moderately to severely active PsA with/without moderate/severe Ps from a US payer's perspective. 


\section{METHODS}

\section{Model Overview}

This economic evaluation was performed using a Markov state transition model to simulate costs and outcomes over a 1-year time horizon in patients with moderately to severely active PsA (defined as presenting with $\geq 3$ swollen and $\geq 3$ tender joints). Two treatment sequences were compared: timely use of TNFi (initiating treatment with adalimumab, etanercept, infliximab, or golimumab; insufficient data were available for certolizumab pegol) versus delayed use (initiating treatment with apremilast), followed by a TNFi in non-responders or those who lost responses.
The model structure (Fig. 1) builds on the probabilistic decision-analytic models used in the Health Technology Assessment of TNFis (York Model), with some adaptations that incorporate the impact of timely versus delayed TNFi use [24]. The length of each Markov cycle was 3 months (i.e., 13 weeks, not including week 0), consistent with labeling recommendations to assess treatment responses at 12-16 weeks and with the British Society of Rheumatology guidelines [25]. The current model was built from a US third-party payer's perspective. Direct costs, including treatment-related and other medical costs, were calculated for each treatment sequence based on Health Assessment Questionnaire

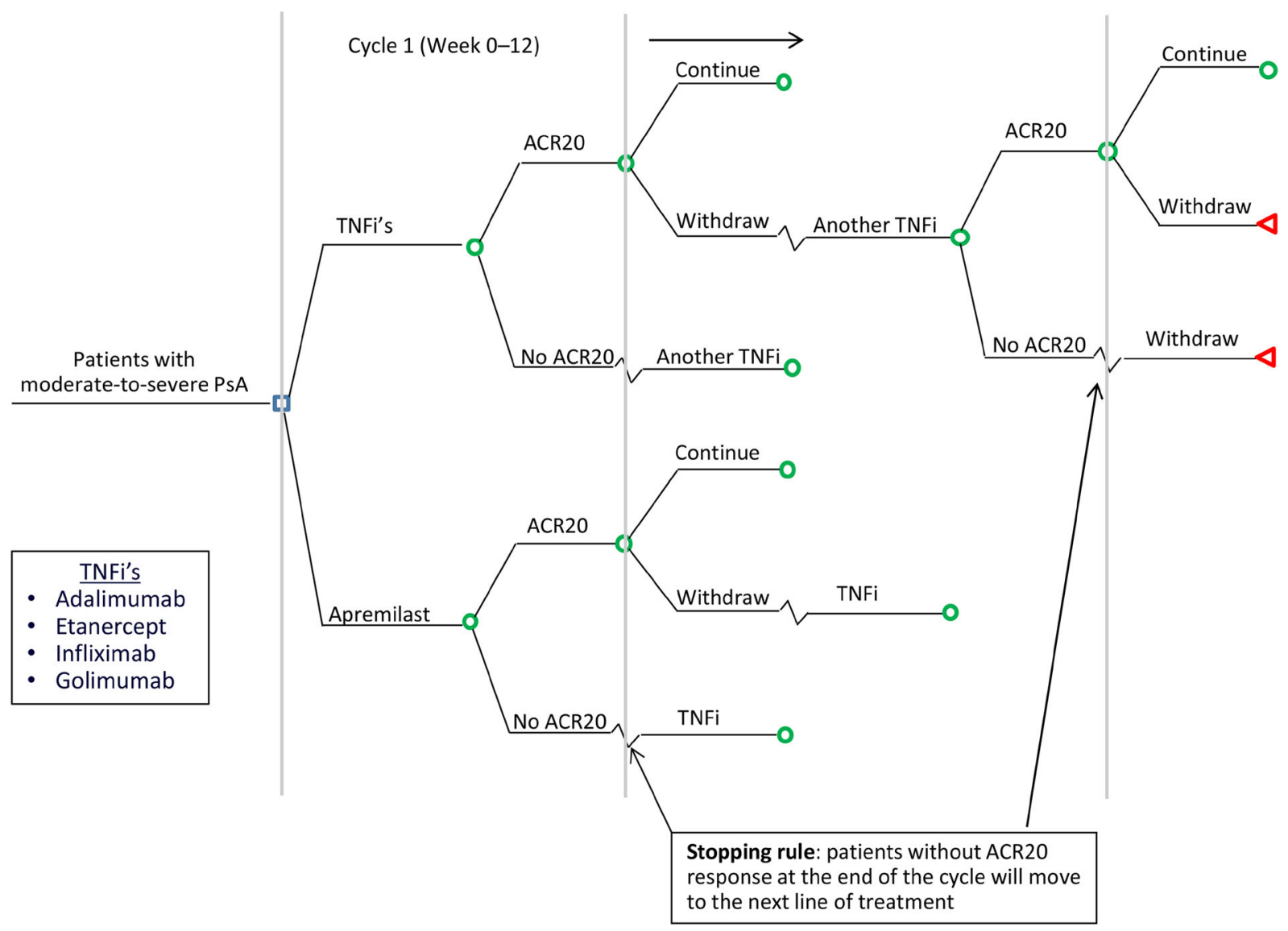

Fig. 1 Model structure. ACR20 American College of Rheumatology 20\% response; Ps $A$ psoriatic arthritis; $T N F i$ Tumor Necrosis Factor inhibitors 
(HAQ) or PASI scores. In addition, the analysis was conducted in the subpopulation with concomitant moderate-to-severe Ps, defined as having $\geq 3 \%$ body surface area involvement.

\section{Model Parameters}

\section{Treatment Effectiveness}

First-Line Effectiveness Patient characteristics at treatment initiation were based on the population enrolled in the Adalimumab Effectiveness in Psoriatic Arthritis Trial (ADEPT; NCT00195689) (Table 1) [26, 27]. Treatment responses were defined as ACR20 responses at month 3 (first cycle), the primary outcome in most PsA RCTs [28]. For first-line mixed TNFis, efficacy data by ACR20, ACR50, and ACR70 responses (i.e. by achieving ACR 20, 50 , and $70 \%$ responses) in the intention-to-treat (ITT) population were pooled from Phase III RCTs, weighted by each TNFi market share (Table 2) [29]. The efficacy of apremilast $30 \mathrm{mg}$ twice daily in the per-protocol population of Phase III RCTs (i.e., PALACE 1-3) was pooled and weighted by the sample size in each trial. Approximately $20 \%$ of patients in these trials had previously received TNFis, while all patients in ADEPT; NCT00195689 were biologic-naive [30]. Because limited information was available regarding efficacy in a biologic-naïve population, the base case model was conducted based on the efficacy noted in all patients in PALACE 1-3, and sensitivity analyses were conducted using ACR20 responses among biologic-naïve patients reported in PALACE 1 [16] and 3 [20].

Clinical efficacy at month 3 was then translated into improvements in HAQ scores relative to baseline (Table 2). This HAQ calculation was developed using patient-level data from the ADEPT trial, reported in the adalimumab manufacturer submission to the
National Institute for Health and Care Excellence (NICE) in the UK [31]. Initial HAQ improvement was conditional on the level of ACR responses achieved (i.e., ACR20, 50, 70) and patient's age, gender, HAQ score, MTX use, and PsA duration at baseline. The algorithm calculated HAQ changes for treatment responders as weighted averages of ACR20, 50 and 70 as well as non-responders. In patients with ACR20 responses at month 3, average decreases in HAQ from baseline were 0.73 and 0.65 for TNFi and apremilast, respectively. Responders were considered to have maintained their initial improvement in HAQ until they withdrew. Patients continued current treatment after month 3 as long as they maintained their initial joint response, regardless of skin response, until discontinuation. Non-responders were assumed to have limited improvements in joint disease at an average decrease in HAQ of 0.13 with both TNFis and apremilast at month 3. Non-responders moved to the next line of therapy at the beginning of the second cycle.

Subsequent-Line

Effectiveness In non-responders or patients who lost ACR20

Table 1 Patient characteristics of the target population

\begin{tabular}{ll}
\hline Description & Value \\
\hline Age, year & 49 \\
Male, \% & $56 \%$ \\
PsA duration, year & 10 \\
Baseline HAQ & 1.3 \\
Ps defined as BSA involvement $\geq 3 \%$ & $40 \%$ \\
Baseline PASI (patients with BSA $\geq 3 \%$ ) & 7.4 \\
MTX use at baseline, \% & $51 \%$ \\
\hline Ps $A \quad$ psoriatic arthritis; $H A Q \quad$ Health Assessment \\
Questionnaire; Ps psoriasis; $B S A$ body surface area; $P A S I$ \\
Psoriasis Area Severity Index; $M T X$ methotrexate
\end{tabular}


responses after 3 months, the model considered subsequent treatment with a different TNFi (timely use of TNFi arm) or initiation of a TNFi (delayed use arm).

Responses for subsequent lines of treatment in the timely use of TNFi arm were assumed to be lower than first-line responses, based on findings of lower efficacy with a 2nd and 3rd TNFi in patients with rheumatoid arthritis (RA) [32]. Reduction in short-term responses were estimated as 25,27 and $37 \%$ relative to first-line ACR20, ACR50 and ACR70 responses, respectively [32]. On the other hand, there is no evidence regarding the effectiveness of delayed TNFi use following apremilast failure-a decrease in efficacy was assumed. This was based on observations from rescue treatment in the ADEPT trial and its open-label 48-week extension, which suggested that patients who initially received TNFis experienced better outcomes than those originally randomized to receive placebo and then received the TNFis [26, 27]. The efficacy of TNFi after apremilast was assumed to decrease by 21,14 and $8 \%$ for ACR20, ACR50 and ACR70 respectively, again based on the rescue arm of the ADEPT RCT [26, 27].

Treatment Withdrawal Based on real-world observations of treatment discontinuation and switching, the model assumed a certain risk of withdrawal from TNFi therapy after each cycle, due to loss of efficacy, adverse events or other reasons. Withdrawal rates for first and subsequent line TNFi use were obtained from a British registry study and assumed to be constant over time (Table 2) [33]. As long-term real-world withdrawal rates have not yet been reported for apremilast, they were assumed to be the same as for TNFis. When patients withdrew from treatment, HAQ scores were assumed to rebound to baseline levels and patients were moved to the next line of treatment at the beginning of the next cycle.

Outcomes for Symptomatic Care For patients who failed a subsequent-line TNFi, the model placed these patients in symptomatic care. This was based on the York model [24], given that treatment guidelines at the time of this analysis did not have recommendations past second-line treatment with TNFi biologics [25, 34, 35]. For patients who failed TNFi treatment, the model assumed that their HAQ score would continue to deteriorate from the last value assigned on subsequent-line treatment at a rate of 0.018 per cycle-based on an assumption of inefficacy with subsequent DMARD treatment for PsA symptoms, as suggested by clinical expert opinion [31].

Mortality Since PsA patients are known to have an increased risk of death compared with the general population [36], an additional mortality risk of $65 \%$ for males and $59 \%$ for females [36] was considered for PsA when estimating mortality and the model assumed no difference in mortality rates between treatments.

Effectiveness in Treating Psoriasis TNFis are approved to treat both joint and skin disease. A subgroup analysis examined clinical improvement, measured by 75\% improvement in PASI as well as ACR20 at each Markov cycle. Effectiveness for both skin and joint manifestations was modeled in this previously defined subgroup. Since there is a positive correlation between responses (e.g., ACR responders are more likely to be PASI responders [37-40]), a bivariate evidence synthesis was performed. Correlations between PASI75 and ACR20 responses were again derived 
Table 2 Effectiveness inputs

\begin{tabular}{|c|c|c|}
\hline Description & Timely TNFi use & Delayed TNFi use \\
\hline Initial treatment & 1 st $\mathrm{TNFi}^{\mathrm{a}}$ & Apremilast \\
\hline \multicolumn{3}{|l|}{ Effectiveness at Month 3 among PsA patients } \\
\hline Probability of achieving ACR20 response & 0.580 & 0.371 \\
\hline Probability of achieving ACR50 response & 0.364 & 0.140 \\
\hline Probability of achieving ACR70 response & 0.155 & 0.030 \\
\hline \multicolumn{3}{|l|}{ Effectiveness at Month 3 among the subgroup with Ps } \\
\hline Probability of achieving PASI50 response & 0.630 & 0.419 \\
\hline Probability of achieving PASI75 response & 0.438 & 0.220 \\
\hline Probability of achieving PASI90 response & 0.260 & 0.110 \\
\hline Probability of achieving ACR20 + PASI75 response ${ }^{\neq}$ & 0.331 & 0.158 \\
\hline \multicolumn{3}{|c|}{ Effectiveness at Month 3 among biologic naïve patients (sensitivity analyses) } \\
\hline Probability of achieving ACR20 response & NA & 0.435 \\
\hline Probability of achieving ACR50 response & NA & 0.171 \\
\hline Probability of achieving ACR70 response & NA & 0.044 \\
\hline Withdrawal rate per cycle after the first cycle & 0.023 & 0.023 \\
\hline Subsequent treatment & 2nd TNFi ${ }^{a}$ & 1st TNFia (delayed) \\
\hline \multicolumn{3}{|l|}{ Effectiveness at Month 3 among PsA patients } \\
\hline Probability of achieving ACR20 response & 0.435 & 0.458 \\
\hline Probability of achieving ACR50 response & 0.266 & 0.314 \\
\hline Probability of achieving ACR70 response & 0.096 & 0.143 \\
\hline \multicolumn{3}{|l|}{ Effectiveness at Month 3 among the subgroup with Ps } \\
\hline Probability of achieving PASI50 response & 0.638 & 0.630 \\
\hline Probability of achieving PASI75 response & 0.448 & 0.438 \\
\hline Probability of achieving PASI90 response & 0.267 & 0.260 \\
\hline Probability of achieving ACR20 + PASI75 response $^{\mathrm{b}}$ & 0.271 & 0.277 \\
\hline Withdrawal rate per cycle after the first cycle & 0.073 & 0.073 \\
\hline \multicolumn{3}{|l|}{ Change in HAQ given an ACR20 response at month $3^{c}$} \\
\hline ACR20 responder & -0.716 & -0.747 \\
\hline ACR20 non-responder & -0.130 & -0.130 \\
\hline HAQ change per cycle while on symptomatic care & 0.018 & 0.018 \\
\hline \multicolumn{3}{|l|}{ Standardized mortality rate for PsA vs. general population } \\
\hline Male & 1.65 & 1.65 \\
\hline
\end{tabular}


Table 2 continued

\begin{tabular}{|c|c|c|}
\hline Description & Timely TNFi use & Delayed TNFi use \\
\hline Female & 1.59 & 1.59 \\
\hline \multicolumn{3}{|c|}{$\begin{array}{l}\text { ACR20, 50, } 70 \text { American College of Rheumatology 20, 50, and 70\% response; } H A Q \text { Health Assessment Questionnaire; } \\
P A S I 50,75 \text {, and } 90 \text { Psoriasis area severity index reduction of 50,75, and 90\%; PsA psoriatic arthritis; Ps psoriasis; TNF } \\
\text { tumor necrosis factor inhibitor } \\
\text { a The treatment effectiveness for mixed TNFi biologics in first and subsequent line were estimated based on the market } \\
\text { shares of biologic use in patients with PsA [29]. The proportions of first-line biologics were estimated to be } 37.0 \% \text { for } \\
\text { adalimumab, 35.1\% for etanercept, } 22.4 \% \text { for infliximab, and } 5.5 \% \text { golimumab, while the shares for the subsequent line were } \\
32.8,32.8,26.6 \text {, and } 7.8 \% \text {, respectively } \\
\text { b The probability of achieving PASI75 response in the first cycle was modeled using a joint distribution with ACR20 using }\end{array}$} \\
\hline $\begin{array}{l}\text { Bayesian bivar } \\
\text { c PASI score } \\
(20 / 50 / 70) \text { re }\end{array}$ & were estimated basec & $(50 / 75 / 90)$ and ACR \\
\hline
\end{tabular}

from the ADEPT trial [26] and used to estimate the probability a patient would have both joint and skin responses (Table 2). This same correlation was used across all treatment groups, assuming the relationship between joint and skin responses are independent of the treatment patients received (as known for TNFis) [24].

\section{Costs}

Based on a third-party payer's perspectives, the base case model considered only direct costs, including treatment-related (product, administration, and monitoring costs) and other medical costs (Table 3). Treatment-related costs were calculated for TNFis based on market share [29], unit prices, and dose per cycle of each therapy. Unit prices for TNFis and apremilast were based on wholesale acquisition costs obtained from ReadyPrice (assessed April 2014) [41]. Dose per cycle was calculated based on product label recommended dosing schedules. Patients receiving TNFis also incurred monitoring costs [42] and patients receiving infliximab incurred administration costs for intravenous infusions administered by a healthcare professional. No monitoring or administration costs were assumed for apremilast. No treatment-related costs were assumed for symptomatic care in the base case model. Costs for using MTX were tested in sensitivity analyses.

The model assumed that PsA patients incurred other medical costs for inpatient and outpatient visits and that costs would increase with severity of arthritis and/or psoriasis [43]. Due to the lack of economic studies on medical costs by HAQ in PsA, the health service costs of treating arthritis were derived from a US-based study that estimated the effect of HAQ on direct costs in patients with RA [43]. The study reported total direct costs corresponding to quartiles of HAQ scores, with $75 \%$ attributed to medical services. A weighted linear regression was fitted using the mid-point of the HAQ score as an independent variable and other medical costs as the dependent variable, weighted by the number of patients in each quartile. This coefficient was estimated to be $\$ 1040$, the mean change in 3-month cost for a 1-unit change in HAQ. Medical costs of treating PsA were estimated as a function of HAQ score at 
Table 3 Cost inputs

Description Cost per cycle (3 months)

Drug $^{\mathrm{a}}$ and drug administration costs

Adalimumab

Etanercept

Golimumab

$\$ 8132$

Infliximab ${ }^{\mathrm{b}}$

$\$ 17,660$ for the first cycle; $\$ 7406$ after the first cycle

Apremilast

$\$ 5531$ for the first cycle; $\$ 5688$ after the first cycle

Monitoring costs

Mixed TNFi

$\$ 143$ for the first cycle; $\$ 45$ after the first cycle

Apremilast

$\$ 0$

Medical costs ${ }^{\mathrm{c}, \mathrm{d}}$

HAQ 0.000-0.625

HAQ 0.626-1.250

$\$ 1590$

HAQ 1.126-1.750

$\$ 2375$

HAQ 1.751-3.000

$\$ 3375$

Medical costs related to Ps

PASI75 responder

PASI75 non-responder

Indirect costs (modeled in the sensitivity analyses)
$\mathrm{HAQ}<0.5$
HAQ 0.5 to $<1.1$
$\$ 4111$
HAQ 1.1 to $<1.6$
HAQ 1.6 to $<2.1$
$\$ 9992$
HAQ 2.1 to $<2.6$
$\mathrm{HAQ} \geq 2.6$
$\$ 9141$

TNFi Tumor necrosis factor inhibitor; HAQ Health Assessment Questionnaire; Ps psoriasis; PASI Psoriasis Area Severity Index

a Treatment costs for mixed TNFi biologics in first and subsequent line were estimated based on the market shares of biologic use in patients with PsA [29]. The proportions of first-line biologics were estimated to be $37.0 \%$ for adalimumab, $35.1 \%$ for etanercept, $22.4 \%$ for infliximab, and $5.5 \%$ golimumab, while the shares for the subsequent line were $32.8,32.8$, 26.6 , and $7.8 \%$, respectively

b The drug and drug administration costs for infliximab included costs for intravenous infusion administered by a healthcare professional ( $\$ 85.8$ per infusion based on the CMS physician fee schedule 2014)

${ }^{c}$ Direct costs extracted from the source included inpatient costs, outpatient costs, drug costs and ancillary costs. Medical costs were assumed to be $75 \%$ of the direct costs

${ }^{\mathrm{d}}$ Linear interpolation was used to estimate the association between costs and HAQ score 
each cycle. For the subgroup of patients with concomitant psoriasis at baseline, patients achieving PASI75 responses were assumed to receive phototherapy once a year. Those who did not achieve PASI75 responses incurred Ps-related medical costs [24], obtained from a real-world claims study of Ps-associated treatment costs [44].

All costs were inflated to 2014 United States Dollar (USD). No discounting was applied to the base case model, due to the short time horizon of the analysis; 3\% discounting rates for both effectiveness and costs were considered when varying time horizon to 5 years in the sensitivity analyses.

\section{Model Outputs}

The base case model estimated total direct costs and effectiveness for each treatment sequence at 1 year after treatment initiation. Among patients with PsA, effectiveness was measured by joint responses (ACR20) and mean time as an ACR20 responder at year 1. Among patients with both joint and skin manifestations, treatment effectiveness was measured by combined ACR20 + PASI75 responses and mean time as ACR20 + PASI75 responders. Numbers needed to treat (NNT) for achievement of ACR20 or ACR20 + PASI75 responses were also reported.

Based on effectiveness and costs outputs, costs per responder for each treatment sequence were calculated. Incremental costs per responder measured the costs per ACR20 (or ACR20 + PASI75) responders with timely vs. delayed use of TNFi.

\section{Sensitivity Analyses}

One-way sensitivity analyses were conducted to examine the impact of change in one key model input or assumption, while holding others at base case values. Model inputs that were varied include treatment costs, other medical costs, efficacy, treatment withdrawal rate, baseline patient characteristics, mortality rate, and time horizon. In addition, the societal perspective, considering both direct and indirect costs, was modeled in sensitivity analyses-indirect costs were estimated as a function of HAQ, based on the similar approach for medical costs. Since no US studies were found to estimate indirect costs associated with PsA, the number of working days missed due to RA were obtained from a German study [45] and the average wage per day in the US [46] was applied to estimate total indirect costs associated with given HAQ scores.

A detailed list of parameters and corresponding ranges/assumptions of the one-way sensitivity analyses are provided in Fig. 2.

The model and sensitivity analyses were conducted using Excel 2010 (Microsoft Corporation, Redmond, WA).

\section{Compliance with Ethics Guidelines}

This article does not contain any new studies with human or animal subjects performed by any of the authors.

\section{RESULTS}

\section{Base Case Analysis}

After 1 year, patients with moderately to severely active PsA who started a TNFi in a timely manner had higher ACR20 responses (70.4\% vs. $59.6 \%)$, and corresponding lower NNTs (1.42 vs. 1.68), than those first treated with apremilast and later receiving a TNFi. Mean times with responses were also longer for timely vs. delayed use of TNFi (7.2 months 
a

Annualized incremental cost per joint responder (2014 US\$)

Drug, administration, and monitoring costs ( $\pm 25 \%)$

$\$ 20,000 \quad \$ 40,000 \quad \$ 60,000 \quad \$ 80,000 \quad \$ 100,000 \quad \$ 120,000 \quad \$ 140,000$

Apremilast ACR response at 3 months (in biologic naïve patients)

Timeframe (5 years)

First-line withdrawal rate for apremilast $(0.007-0.038)$

Indirect cost (Yes)

First-line withdrawal rate for TNFi (0.007-0.038)

No adjustment for efficacy in subsequent lines

Alternative direct cost (Yes)

Ps-related cost $( \pm 25 \%)$

Baseline age, year (40-60)

Symptomatic care cost ( $\$ 503$ every 3 months)

Baseline HAQ (0.5-2)

No additional mortality risk for PsA population

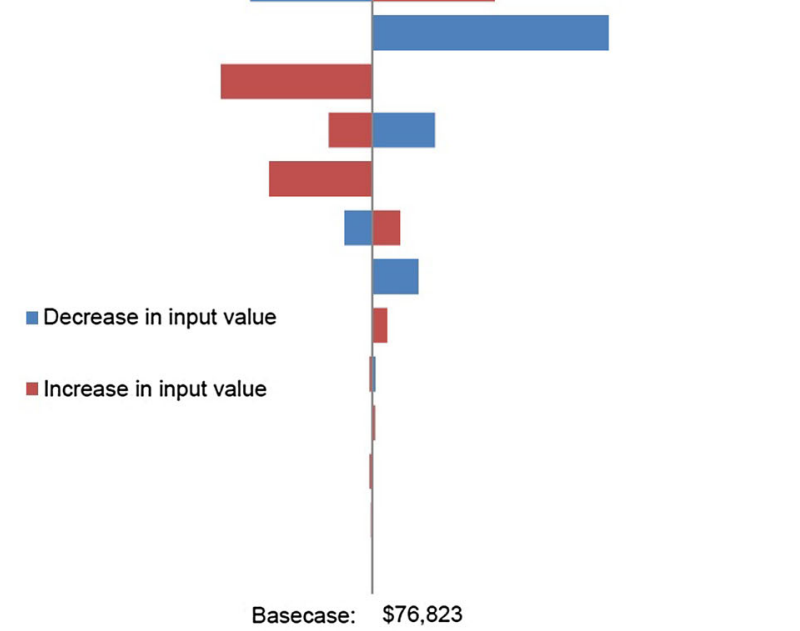

b

Annualized incremental cost per joint + skin responder (2014 US\$)

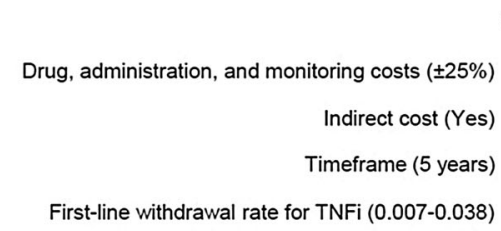

First-line withdrawal rate for apremilast $(0.007-0.038)$

Alternative direct cost (Yes)

Ps-related cost $( \pm 25 \%)$

No adjustment for efficacy in subsequent lines

Baseline age, year (40-60)

Symptomatic care cost ( $\$ 503$ every 3 months)

Baseline HAQ (0.5-2)

No additional mortality risk for PsA population

Apremilast $A C R$ response at 3 months (in biologic naïve patients)

$\$ 0$

$\$ 20,000$

$\$ 40,000$

$\$ 60,000 \quad \$ 80,000$

$\$ 100,000$

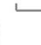

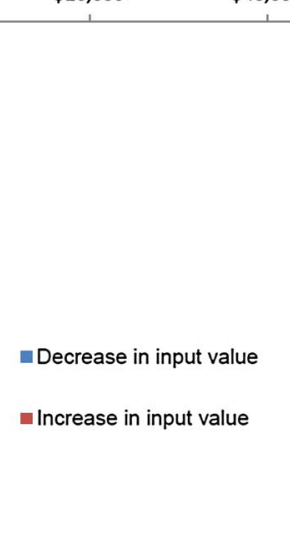


4 Fig. 2 Tornado diagram of one-way sensitivity analyses for incremental costs per responder. Top panel patients with PsA (Incremental cost per ACR20 responder). Bottom panel Patients with PsA and psoriasis (Incremental cost per ACR20 + PASI75 responder). ACR American College of Rheumatology; $H A Q$ Health Assessment Questionnaire; Ps $A$ psoriatic arthritis; $P s O$ psoriasis; TNFi Tumor Necrosis Factor inhibitors Alternative medical costs inputs were obtained from Kobelt et al. 2002 [63]. The costs were inflated to 2014 USD

vs. 5.8 months). Patients with timely TNFi treatment incurred higher costs $(\$ 39,754$ vs. $\$ 31,513)$. The cost per ACR20 responder was similar between the two treatment groups ( $\$ 56,492$ vs. $\$ 52,835$, respectively) and the 1-year incremental cost per ACR20 responder was $\$ 76,823$ for timely vs delayed TNFi use (Table 4a).

Among patients with concomitant moderate to severe Ps, timely TNFi use was associated with higher combined ACR20 + PASI75 responses (41.0\% vs. $30.0 \%)$, corresponding to lower NNTs (2.44 vs. 3.33), with longer durations of response (4.2 months vs. 2.8 months). Timely TNFi treatment was also associated with higher costs during the 1 st year ( $\$ 41,437$ vs. $\$ 33,510$ ), resulting in the incremental cost per ACR20 + PASI75 responder as $\$ 71,791$ for timely vs delayed use. However, cost per ACR20 + PASI75 responder was lower for initial treatment with TNFi than apremilast $(\$ 100,954$ vs. $\$ 111,686)$ (Table $4 b)$.

\section{One-Way Sensitivity Analyses}

In the one-way sensitivity analyses, incremental cost per ACR20 responder ranged from \$51,274 to $\$ 116,624$. Factors with the largest impact on incremental costs were treatment-related costs, apremilast ACR20 responses at 12 weeks, and a longer time horizon (i.e., 5 years). Incremental costs per ACR20 + PASI75 responders ranged from $\$ 51,760$ to $\$ 91,822$ and were most sensitive to treatment-related costs, indirect costs, and a longer time horizon (Fig. 2).

\section{DISCUSSION}

Recently, several new therapies have been approved for PsA, prompting further assessments of treatment options $[47,48]$ and their cost-effectiveness [24, 49-51], as well as issuance of new treatment recommendations [13]. In patients with active PsA, TNFis have proven highly effective in treating PsA symptoms and inhibiting structural progression [52-54]. A newly introduced agent, apremilast, has been shown to be effective in treating the signs and symptoms of PsA. A few other studies have attempted to investigate the economic impact of using apremilast before or instead of TNFi treatment and concluded that apremilast is a more cost-effective option over a lifetime horizon [55], with lower costs per responder relative to TNFis in a one-year treatment model [56]. However, from the available published information, these previously published models did not consider concomitant Ps or structural progression in PsA, and still produced only modest cost savings with the use of apremilast.

In the present economic model, patients initially treated with a TNFi had higher responses and lower NNTs than those initially receiving apremilast. Although patients with timely use of a TNFi had higher treatment-related costs than the delayed use group after 1 year, these costs were partially offset by lower other medical costs. Based on costs-per-responder estimates, total annual costs for ACR20 responders were similar in both groups, although slightly higher with 
Table 4 Based case results (2014 USD)

$\begin{array}{lll}\begin{array}{l}\text { Timely TNFi use } \\ (\text { Arm A })\end{array} & \begin{array}{l}\text { Delayed TNFi use } \\ \text { (Arm B) }\end{array} & \begin{array}{l}\text { Difference } \\ \text { (Arm A-Arm B) }\end{array}\end{array}$

A. Patients with PsA

Costs

Direct costs

$\begin{array}{lll}\$ 39,754 & \$ 31,513 & \$ 8241 \\ \$ 31,751 & \$ 22,904 & \$ 8847 \\ \$ 8003 & \$ 8609 & -\$ 606\end{array}$

Effectiveness

$\%$ of ACR20 responder

$70.4 \%$

$59.6 \%$

$10.7 \%$

Number needed to treat ${ }^{a}$

1.42

1.68

9.32

Mean time with joint response (month)

5.8

1.4

Cost per responder

Cost per ACR20 responder

$\$ 56,492$

$\$ 52,835$

$\$ 3657$

Incremental cost per joint responder

Arm A vs. Arm B $\$ 76,823$

B. Subgroup of patients with PsA and psoriasis

\section{Costs}

Direct costs

Treatment-related costs

Other medical costs

Effectiveness

$\%$ of ACR20 + PASI75 responder

$41.0 \%$

2.44

$\$ 100,954$

Cost per responder

Cost per ACR20 + PASI75 responder

Incremental cost per joint and skin responder

$\begin{array}{lll}41.0 \% & 30.0 \% & 11.0 \%\end{array}$

3.33

9.06

$-\$ 10,732$

Arm A vs. Arm B

$\$ 71,791$

ACR20 American College of Rheumatology 20\% response; PASI Psoriasis Area Severity Index; PsA psoriatic arthritis; TNFi Tumor Necrosis Factor inhibitors

${ }^{a}$ Number needed to treat is defined as the average number of patients who need to be treated for one responder. The comparison results (in italics) between the two arms should be interpreted as the number of patients who need to be treated to observe one responder in arm $\mathrm{A}$ versus arm $\mathrm{B}$ 
timely use. When both joint and skin responses were accounted for, responses and cost trends were similar to analyses that were based on joint responses only, but total costs were much lower for timely use vs. delayed use of TNFis. These results indicate that, overall, timely treatment with TNFis is more expensive than delayed treatment, but for those patients with both skin and joint manifestations, cost savings can be substantial. Since $46-83 \%$ patients enrolled in TNFi RCTs [57] have manifestations of Ps, this finding underscores the need to consider effectiveness for both joint and skin disease when assessing treatments for PsA.

This study provides important information on economic and clinical outcomes associated with choice of TNFis versus apremilast as 1st-line treatment for moderately to severely active PsA, with careful attention to presenting an accurate model of the disease. Nonetheless, this still remains a model, which cannot account for the natural history of the disease or all aspects of its treatment. Sensitivity analyses were performed to identify largest areas of uncertainty [58] in the model-indicating that, among other factors, ACR20 responses with apremilast treatment and 1st-line withdrawal rates following apremilast had a large impact on the model results. Due to lack of available information, some assumptions were necessary to incorporate into the model: ACR20 responses were derived from RCTs with apremilast that included mixed populations of treatment-naïve and TNFi-exposed patients. Based on reported efficacy, it is possible that treatment-naïve patients receiving apremilast might achieve higher responses than in the mixed population trials-although ACR20 rates at week 14 were $28-31 \%$ in the PALACE 4 trial (NCT01307423) in DMARD (synthetic and biologic)-naïve patients [59], below those observed in PALACE 1-3 (which were used in the present analysis). Therefore, sensitivity analyses were conducted to include a compensatory factor for ACR20 responses with apremilast, increasing response rates from the observed $37 \%$ to an estimated $43 \%$, based on the subgroup analysis in biologic-naïve patients, as reported in PALACE 1 and 3. Furthermore, since there is no information regarding the degree to which the effectiveness of TNFis may be impacted by prior use of apremilast, the model used rescue data from RCTs to estimate the difference between timely vs. delayed initiation of a TNFi. Nonetheless, the effect of this latter adjustment on the primary findings was not substantial, and the model assumed the same withdrawal rates for the two treatment sequences, as there were no long-term observational data with apremilast.

Despite these sensitivity analyses, several limitations of the current model must be acknowledged. The effectiveness mode inputs were mainly based on RCTs, but patients enrolled in trials differ from those treated in routine clinical practice, and trial design may impose additional treatment restrictions not generally observed in clinical practice. Results may therefore not be generalizable to the greater PsA patient population.

There are no head-to-head trials comparing the two modeled treatment sequences; therefore, effectiveness data were obtained from a mix of several RCTs and observational studies, and the comparative results may be biased by differences between populations and study design. For example, while all RCTs for TNFis included in the present study were based on the ITT population, all RCTs for apremilast were based on the per-protocol population. In addition, RCTs with apremilast (PALACE 1-3 $[16,20,60,61])$ included both TNFi-naïve and -experienced patients, and a subgroup analysis of all modeled outcomes was not available for TNFi-naïve patients. The present analysis may 
have underestimated ACR20 responses in TNFi-naïve patients, which could have biased results against initial use of apremilast. On the other hand, as there are no data that apremilast can inhibit the progression of structural damage, the current analysis may be conservative relative the cost-efficacy of apremilast vs a TNFi.

The model included several assumptions regarding the effectiveness of 1 st versus 2 nd-line TNFi use, and early vs. delayed treatment; these assumptions were tested in sensitivity analyses and the model was not sensitive to the assumption of decreased efficacy with prior exposure. While sequential use of TNFis is common in clinical practice, the model assumes that patients receive no treatment (i.e., symptomatic care) after subsequent TNFi therapy—as assumed by other models of PsA treatment [24]. However, the newly published GRAPPA recommendations suggest possible rescue of response with IL-12/23 or IL-17 inhibitors and PDE4i in patients who have TNFi failure [13]. At the time of model development, the IL-17 inhibitors had not yet been approved for this indication and their clinical evidence after two TNFis or one TNFi and one PDE4i failure are lacking. Therefore, the current model did not consider these treatment options after subsequent TNFi failure.

Finally, uncertainty [62] remains regarding progression of HAQ scores with and without TNFi and apremilast treatment and their short-term effectiveness in PsA. Further research is needed on these topics, as all current cost-effectiveness models of treatment for PsA rely on assumptions for these inputs [24].

\section{CONCLUSION}

Timely use of TNFis is a cost-effective strategy for management of moderately to severely active PsA, due to greater improvements in joint and skin manifestations than observed with delayed initiation of TNFis. Furthermore, timely use of TNFis can reduce medical costs, which can partially offset the higher treatment-related costs compared with delayed TNFi treatment. Future research on the impact of delayed use of TNFis on patients' health-related quality of life is warranted.

\section{ACKNOWLEDGMENTS}

Sponsorship for this study and article processing charges was funded by AbbVie Inc., North Chicago, Illinois, United States. Medical writing assistance was provided by Ana Bozas, $\mathrm{PhD}$, an employee of Analysis Group, Inc. We would like to thank Yichen Zhong, a former employee of Analysis Group, Inc. for assisting with data analysis. AbbVie provided funding to Analysis Group, Inc. for this work. All named authors meet the International Committee of Medical Journal Editors (ICMJE) criteria for authorship for this manuscript, take responsibility for the integrity of the work as a whole, and have given final approval to the version to be published.

Disclosures. Vibeke Strand is a consultant to AbbVie, Alder, Amgen, BMS, Celgene, Genentech, Janssen, Novartis, Pfizer and UCB and has served on advisory boards for AbbVie, Amgen, BMS, Celgene, Genentech, Janssen, Novartis, Pfizer, and UCB. Elaine Husni is a consultant to AbbVie and Janssen, and has served on advisory boards for AbbVie, Celgene, Genentech, Bristol-Myers Squibb, Lilly, Pfizer, Novartis, and Janssen. James Signorovitch is a full-time employee of Analysis Group, Inc. which has received consulting fee from AbbVie to partner on this research. Zheng-Yi Zhou is a 
full-time employee of Analysis Group, Inc. which has received consulting fee from AbbVie to partner on this research. Jenny Griffith is a full-time AbbVie employee and owns AbbVie stock. Arijit Ganguli is a full-time AbbVie employee and owns AbbVie stock.

Compliance with Ethics Guidelines. This article does not contain any new studies with human or animal subjects performed by any of the authors.

Open Access. This article is distributed under the terms of the Creative Commons Attribution-NonCommercial 4.0 International License (http://creativecommons.org/licenses/ by-nc/4.0/), which permits any noncommercial use, distribution, and reproduction in any medium, provided you give appropriate credit to the original author(s) and the source, provide a link to the Creative Commons license, and indicate if changes were made.

\section{REFERENCES}

1. Rachakonda TD, Schupp CW, Armstrong AW. Psoriasis prevalence among adults in the United States. J Am Acad Dermatol. 2014;70(3):512-6.

2. Ficco HM, Citera G, Cocco JAM. Prevalence of psoriatic arthritis in psoriasis patients according to newer classification criteria. Clin Rheumatol. 2014;33(2):243-6.

3. Prey S, Paul C, Bronsard V, Puzenat E, Gourraud PA, Aractingi $S$, et al. Assessment of risk of psoriatic arthritis in patients with plaque psoriasis: a systematic review of the literature. J Eur Acad Dermatol Venereol. 2010;24(Suppl 2):31-5.

4. Wollina U, Unger L, Heinig B, Kittner T. Psoriatic arthritis. Dermatol Ther. 2010;23(2):123-36.

5. Day MS, Nam D, Goodman S, Su EP, Figgie M. Psoriatic arthritis. J Am Acad Orthop Surg. 2012;20(1):28-37.

6. Leung YY, Tam LS, Kun EW, Li EK. Impact of illness and variables associated with functional impairment in Chinese patients with psoriatic arthritis. Clin Exp Rheumatol. 2008;26(5):820-6.

7. Tillett W, Shaddick G, Askari A, Cooper A, Creamer $P$, Clunie $G$, et al. Factors influencing work disability in psoriatic arthritis: first results from a large UK multicentre study. Rheumatology (Oxford). 2015;54(1):157-62.

8. Wallenius $\mathrm{M}$, Skomsvoll JF, Koldingsnes W, Rodevand E, Mikkelsen K, Kaufmann C, et al. Work disability and health-related quality of life in males and females with psoriatic arthritis. Ann Rheum Dis. 2009;68(5):685-9.

9. Osterhaus JT, Purcaru O. Discriminant validity, responsiveness and reliability of the arthritis-specific Work Productivity Survey assessing workplace and household productivity in patients with psoriatic arthritis. Arthritis Res Ther. 2014;16(4):R140.

10. Cortesi PA, Scalone L, D'Angiolella L, Belisari A, Fusco F, Olivieri I, et al. Systematic literature review on economic implications and pharmacoeconomic issues of psoriatic arthritis. Clin Exp Rheumatol. 2012;30(4 Suppl 73):S126-31.

11. Kawalec P, Malinowski KP. The indirect costs of psoriatic arthritis: systematic review and meta-analysis. Expert Rev Pharmacoecon Outcomes Res. 2015;15(1):125-32.

12. Lee S, Mendelsohn A, Sarnes E. The burden of psoriatic arthritis: a literature review from a global health systems perspective. P T. 2010;35(12):680-9.

13. Coates LC, Kavanaugh A, Mease PJ, Soriano ER, Laura Acosta Felquer M, Armstrong AW, et al. Group for research and assessment of psoriasis and psoriatic arthritis: Treatment recommendations for psoriatic arthritis 2015. Arthritis Rheumatol. 2016;68(5):1060-71.

14. Felquer ML, Soriano ER. New treatment paradigms in psoriatic arthritis: an update on new therapeutics approved by the U.S. Food and Drug Administration. Curr Opin Rheumatol. 2015;27(2):99-106.

15. Schett G, Wollenhaupt J, Papp K, Joos R, Rodrigues $\mathrm{JF}$, Vessey AR, et al. Oral apremilast in the treatment of active psoriatic arthritis: results of a multicenter, randomized, double-blind, placebo-controlled study. Arthritis Rheum. 2012;64(10):3156-67.

16. Kavanaugh A, Mease PJ, Gomez-Reino JJ, Adebajo AO, Wollenhaupt J, Gladman DD, et al. Treatment of psoriatic arthritis in a phase 3 randomised, placebo-controlled trial with apremilast, an oral phosphodiesterase 4 inhibitor. Ann Rheum Dis. 2014;73(6):1020-6. 
17. Kavanaugh A, Mease PJ, Gomez-Reino JJ, Adebajo AO, Wollenhaupt J, Gladman DD, et al. Longterm (52-week) results of a phase III randomized, controlled trial of apremilast in patients with psoriatic arthritis. J Rheumatol. 2015;42(3):479-88.

18. Celgene Corporation. PALACE 3: Efficacy and Safety Study of Apremilast to Treat Active Psoriatic Arthritis: U.S. National Institutes of Health (NIH); $2015 . \quad$ https://clinicaltrials.gov/ct2/show/ NCT01212770. Accessed May 2016

19. Celgene Corporation. PALACE 2: Efficacy and safety study of apremilast to treat active psoriatic arthritis: U.S. National Institutes of Health (NIH); 2015. https://clinicaltrials.gov/ct2/show/NCT01212757. Accessed May 2016

20. Edwards CJ, Blanco FJ, Crowley J, Hu C, Stevens RM, Birbara CA. 212. Long-term 52-week results of palace 3 , a phase 3 , randomized, controlled trial of apremilast, an oral phosphodiesterase 4 inhibitor, in patients with psoriatic arthritis and current skin involvement. Rheumatology. 2014;53(suppl 1):i138-9.

21. Palfreeman AC, McNamee KE, McCann FE. New developments in the management of psoriasis and psoriatic arthritis: a focus on apremilast. Drug Des Devel Ther. 2013;7:201-10.

22. D'Angelo S, Palazzi C, Olivieri I. Psoriatic arthritis: treatment strategies using biologic agents. Reumatismo. 2012;64(2):113-21.

23. Betts KA, Griffith J, Friedman A, Zhou ZY, Signorovitch JE, Ganguli A. An indirect comparison and cost per responder analysis of adalimumab, methotrexate and apremilast in the treatment of methotrexate-naive patients with psoriatic arthritis. Curr Med Res Opin. 2016;32(4):721-9.

24. Rodgers M, Epstein D, Bojke L, Yang H, Craig D, Fonseca $\mathrm{T}$, et al. Etanercept, infliximab and adalimumab for the treatment of psoriatic arthritis: a systematic review and economic evaluation. Health Technol Assess. 2011;15(10):i-Xxi, 1-329.

25. Coates LC, Tillett W, Chandler D, Helliwell PS, Korendowych E, Kyle S, et al. The 2012 BSR and BHPR guideline for the treatment of psoriatic arthritis with biologics. Rheumatology (Oxford). 2013;52(10):1754-7.

26. Mease PJ, Gladman DD, Ritchlin CT, Ruderman EM, Steinfeld SD, Choy EH, et al. Adalimumab for the treatment of patients with moderately to severely active psoriatic arthritis: results of a double-blind, randomized, placebo-controlled trial. Arthritis Rheum. 2005;52(10):3279-89.
27. Gladman DD, Mease PJ, Ritchlin CT, Choy EH, Sharp JT, Ory PA, et al. Adalimumab for long-term treatment of psoriatic arthritis: forty-eight week data from the adalimumab effectiveness in psoriatic arthritis trial. Arthritis Rheum. 2007;56(2):476-88.

28. Felson DT, Anderson JJ, Boers M, Bombardier C, Chernoff M, Fried B, et al. The American College of Rheumatology preliminary core set of disease activity measures for rheumatoid arthritis clinical trials. The Committee on Outcome Measures in Rheumatoid Arthritis Clinical Trials. Arthritis Rheum. 1993;36(6):729-40.

29. AbbVie Inc. AbbVie Market Share Research. [unpublished data]. In press. 2012.

30. Mease PJ, Kavanaugh A, Gladman DD, Adebajo AO, Gomez-Reino JJ, Wollenhaupt J, et al., editors. Long-term safety and tolerability of apremilast, an oral phosphodiesterase 4 inhibitor, in patients with psoriatic arthritis: pooled safety analysis of three phase 3, randomized, controlled trials. Arthritis and rheumatism. Hoboken: Wiley-Blackwell; 2013.

31. Abbott Laboratories Ltd. Multiple technology appraisal of adalimumab, etanercept and infliximab for psoriatic arthritis. National Institute for Health and Clinical Excellence (NICE) Health Technology Appraisal 2009 [updated 2009. http:// www.nice.org.uk/guidance/ta199/history. http:// www.nice.org.uk/guidance/TA199/documents/ psoriatic-arthritis-etanercept-infliximab-adalimumabreview-acd-manufacturer-submissions-abbott2. http:// www.nice.org.uk/guidance/TA199/documents/ psoriatic-arthritis-etanercept-infliximab-adalimumabreview-acd-consultee-and-commentator-commentson-the-assessment-report-abbott-ar2. Accessed May 2016

32. Rendas-Baum R, Wallenstein GV, Koncz T, Kosinski M, Yang M, Bradley J, et al. Evaluating the efficacy of sequential biologic therapies for rheumatoid arthritis patients with an inadequate response to tumor necrosis factor-alpha inhibitors. Arthritis Res Ther. 2011;13(1):R25.

33. Saad AA, Ashcroft DM, Watson KD, Hyrich KL, Noyce PR, Symmons DP, et al. Persistence with anti-tumour necrosis factor therapies in patients with psoriatic arthritis: observational study from the British Society of Rheumatology Biologics Register. Arthritis Res Ther. 2009;11(2):R52.

34. Gossec L, Smolen JS, Gaujoux-Viala C, Ash Z, Marzo-Ortega H, van der Heijde D, et al. European League Against Rheumatism recommendations for the management of psoriatic arthritis with pharmacological therapies. Ann Rheum Dis. 2012;71(1):4-12. 
35. Ritchlin CT, Kavanaugh A, Gladman DD, Mease PJ, Helliwell P, Boehncke WH, et al. Treatment recommendations for psoriatic arthritis. Ann Rheum Dis. 2009;68(9):1387-94.

36. Wong K, Gladman DD, Husted J, Long JA, Farewell VT. Mortality studies in psoriatic arthritis: results from a single outpatient clinic. I. Causes and risk of death. Arthritis Rheum. 1997;40(10):1868-72.

37. Rodgers M, Epstein D, Bojke L, Yang H, Craig D, Fonseca T, et al. Clarifications from manufacturers Southampton (UK): NIHR Journals Library. 2011. http://www.ncbi.nlm.nih.gov/books/NBK109492/. Accessed May 2016

38. Mease PJ, Antoni CE. Psoriatic arthritis treatment: biological response modifiers. Ann Rheum Dis. 2005;64(suppl 2):ii78-ii82.

39. Mease PJ. Adalimumab in the treatment of arthritis. Ther Clin Risk Manag. 2007;3(1):133-48.

40. Ritchlin C, Mease P, Sasso E, editors. Correlation of skin and joint responses in psoriatic arthritis: a subanalysis of adept. Annals of the Rheumatic Diseases. Tavistock Square: BMJ Publishing Group British Med Assoc House; 2006.

41. Truven Health Analytics Inc. ReadyPrice: Truven Health Analytics Inc. 2015. http://www. micromedexsolutions.com/home/dispatch. Accessed May 2016

42. AbbVie Inc. HUMIRA (adalimumab) injection, for subcutaneous use Silver Spring, MD: U.S. Food and Drug Administration; 2014 [1-80]. http://www. accessdata.fda.gov/drugsatfda_docs/label/2014/ 125057s367lbl.pdf. Accessed May 2016

43. Yelin E, Wanke LA. An assessment of the annual and long-term direct costs of rheumatoid arthritis: the impact of poor function and functional decline. Arthritis Rheum. 1999;42(6):1209-18.

44. Yu AP, Tang J, Xie J, Wu EQ, Gupta SR, Bao Y, et al. Economic burden of psoriasis compared to the general population and stratified by disease severity. Curr Med Res Opin. 2009;25(10):2429-38.

45. Schadlich PK, Zeidler H, Zink A, Gromnica-Ihle E, Schneider M, Straub C, et al. Modelling cost effectiveness and cost utility of sequential DMARD therapy including leflunomide in rheumatoid arthritis in Germany: I. Selected DMARDs and patient-related costs. Pharmacoeconomics. 2005;23(4):377-93.

46. Bureau of Labor Statistics UDoL. May 2014 National Occupational Employment and Wage Estimates United States: US Department of Labor. 2014. http://www.bls.gov/oes/current/oes_nat.htm. Accessed May 2016
47. Ash Z, Gaujoux-Viala C, Gossec L, Hensor EM, FitzGerald $\mathrm{O}$, Winthrop $\mathrm{K}$, et al. A systematic literature review of drug therapies for the treatment of psoriatic arthritis: current evidence and meta-analysis informing the EULAR recommendations for the management of psoriatic arthritis. Ann Rheum Dis. 2012;71(3):319-26.

48. Coates LC, Kavanaugh A, Ritchlin CT, Committee GTG. Systematic review of treatments for psoriatic arthritis: 2014 update for the GRAPPA. J Rheumatol. 2014;41(11):2273-6.

49. Cawson MR, Mitchell SA, Knight C, Wildey H, Spurden D, Bird A, et al. Systematic review, network meta-analysis and economic evaluation of biological therapy for the management of active psoriatic arthritis. BMC Musculoskelet Disord. 2014;15:26.

50. Bojke L, Epstein D, Craig D, Rodgers M, Woolacott $\mathrm{N}$, Yang $\mathrm{H}$, et al. Modelling the cost-effectiveness of biologic treatments for psoriatic arthritis. Rheumatology (Oxford). 2011;50(Suppl 4):iv39-iv47.

51. Barra L, Pope JE, Payne M. Real-world anti-tumor necrosis factor treatment in rheumatoid arthritis, psoriatic arthritis, and ankylosing spondylitis: cost-effectiveness based on number needed to treat to improve health assessment questionnaire. J Rheumatol. 2009;36(7):1421-8.

52. Eder L, Thavaneswaran A, Chandran V, Gladman DD. Tumour necrosis factor alpha blockers are more effective than methotrexate in the inhibition of radiographic joint damage progression among patients with psoriatic arthritis. Ann Rheum Dis. 2014;73(6):1007-11.

53. Goulabchand R, Mouterde G, Barnetche T, Lukas C, Morel J, Combe B. Effect of tumour necrosis factor blockers on radiographic progression of psoriatic arthritis: a systematic review and meta-analysis of randomised controlled trials. Ann Rheum Dis. 2014;73(2):414-9.

54. Soriano ER, McHugh NJ. Therapies for peripheral joint disease in psoriatic arthritis. A systematic review. J Rheumatol. 2006;33(7):1422-30.

55. Tencer $T$, Clancy Z, Cawston H, Damera V, Berardi A, Cure S. Economic evaluation of sequencing strategies in the treatment of psoriatic arthritis in the United States. Value Health. 2014;17(3):A46.

56. Tencer T, Clancy Z, Zhang F. Cost per responder of apremilast versus etanercept and adalimumab in patients with active psoriatic arthritis. Value Health. 2014;17(7):A376. 
57. Lemos LL, de Oliveira Costa J, Almeida AM, Junior HO, Barbosa MM, Kakehasi AM, et al. Treatment of psoriatic arthritis with anti-TNF agents: a systematic review and meta-analysis of efficacy, effectiveness and safety. Rheumatol Int. 2014;34(10):1345-60.

58. Jackson $\mathrm{CH}$, Bojke L, Thompson SG, Claxton $\mathrm{K}$, Sharples LD. A framework for addressing structural uncertainty in decision models. Med Decis Mak Int J Soc Med Decis Mak. 2011;31(4):662-74.

59. Celgene Corporation. Efficacy and Safety Study of Apremilast to Treat Active Psoriatic Arthritis (PsA) (PALACE4): U.S. National Institutes of Health; 2015. https://www.clinicaltrials.gov/ct2/show/ results/NCT01307423. Accessed May 2016

60. Cutolo M, Myerson GE, Fleischmann RM, Lioté F, Díaz-González F, Van den Bosch F, et al. Long-term (52-week) results of a phase 3 , randomized, controlled trial of apremilast, an oral phosphodiesterase 4 inhibitor, in patients with psoriatic arthritis (PALACE 2). [abstract]. Arthritis Rheum. 2013;65(Suppl 10):815.

61. US Department of Health and Human Services. Statistical review-clinical study (apremilast). http:// www.accessdata.fda.gov/drugsatfda_docs/nda/2014/ 205437Orig1s000StatR.pdf. Accessed May 2016

62. Bojke L, Claxton K, Bravo-Vergel Y, Sculpher M, Palmer S, Abrams K. Eliciting distributions to populate decision analytic models. Value Health. 2010;13(5):557-64.

63. Kobelt G, Jonsson L, Lindgren P, Young A, Eberhardt K. Modeling the progression of rheumatoid arthritis: a two-country model to estimate costs and consequences of rheumatoid arthritis. Arthritis Rheum. 2002;46(9):2310-9. 